\title{
Revendo uma das críticas às descrições missionárias*
}

\author{
Missionary descriptions: a critique revisited
}

\author{
Maria Carlota Rosa \\ Universidade Federal do Rio de Janeiro
}

\section{Abstract}

This paper discusses a continuously repeated statement about the traditional grammatical descriptions which says that they reduced the structures of all languages to the structure of Latin. The discussion is based on the analysis of three language descriptions written in the 17 th century by Jesuitical missionaries. From these grammatical works a different sense for the expression "identical to Latin" emerges: a set of structural aspects to which the grammarian could not fail to give attention.

\section{Keywords}

Greek and Latin grammatical tradition, Missionary grammars, 17th century, Society of Jesus, Manuel Álvares, Vernacular languages and standard languages, Pedro Dias, Ludovico Vicenzo Mamiani della Rovere, Heinrich Roth.

\section{Resumo}

Este trabalho discute a afirmação continuamente repetida de que as descrições tradicionais transpuseram cegamente aspectos da gramática latina para a descrição de outras línguas, impondo a estas um molde que as transformava a todas em línguas semelhantes ao latim. Tomando-se para análise três gramáticas missionárias, produzidas para missões jesuítas no século XVII, constata-se que 
as descrições estão plenas de evidências de que as diferenças foram percebidas e apontadas, mesmo caso se leve em conta que o religioso não contava com instrumental adequado para tal tarefa. A leitura de obras desse período revela que "semelhante ao latim" não pode ser compreendido como equivalente a 'sem diferenças em relação ao latim, afora o vocabulário', mas como equivalente a um inventário de características estruturais cujo funcionamento na língua em análise tinha de ser focalizado.

\section{Palavras-chave}

Tradição greco-latina, Gramáticas missionárias, Século XVII, Companhia de Jesus, Manuel Álvares, Vernáculos e línguas padronizadas, Pedro Dias, Ludovico Vicenzo Mamiani della Rovere, Heinrich Roth 


\section{INTRODUÇÃO}

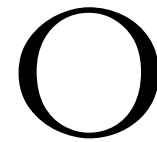

presente trabalho discute uma crítica às descrições lingüísticas tradicionais muitas vezes repetida, a saber, a de que esses trabalhos tiveram por meta moldar a gramática de cada língua descrita à gramática do latim, de modo a obscurecer, ou mesmo a negar, as diferenças existentes entre elas e o latim. Tem-se por objetivo demonstrar que o predicado "semelhante ao latim" não implicava a negação de diferenças entre o latim e as demais línguas e sim que havia um conjunto de aspectos estruturais que o gramático não se poderia esquivar de descrever. Para demonstrar essa hipótese, tomam-se para exemplo três gramáticas missionárias de fins do século XVII que constituem a primeira tentativa européia de descrição dessas línguas de famílias diferentes e continentes distintos. Seus autores foram missionários da Companhia de Jesus. As três gramáticas são aqui analisadas em sua organização, postas em confronto com a Institutione grammatica (1572) do também jesuíta Manuel Álvares (1526-1583), a gramática recomendada pela Companhia de Jesus.

Descrições de línguas vernáculas européias haviam começado a ser escritas na Idade Média e filiavam-se, implícita ou explicitamente, a um gramático latino cuja obra gozasse de prestígio na época. Assim, por exemplo, a primeira descrição conhecida de um vernáculo no mundo românico é o Donatz Proensals, escrita em provençal e em latim, provavelmente na Itália, por volta de 1240 (VINEIS \& MAIERÙ, 1990, p. 189). O título da obra já demonstra a influência de Aelius Donatus ( $c a .400$ a.D), grande nome gramatical latino do final da Alta Antigüidade e início da Idade Média. A referência ao autor da Ars Minor e da Ars Maior não impediu, porém, o autor medieval de reconhecer no provençal características que o latim não apresentava - por exemplo, um sistema de apenas dois casos nominais (VINEIS \& MAIERÙ, 1990, p. 189). Tal procedimento seria repetido nas descrições 
de muitas outras línguas ao longo dos séculos seguintes, especialmente após os Descobrimentos. É o caso dos trabalhos aqui focalizados, nos quais, de modo mais ou menos direto, é possível perceber a influência da gramática latina de Manuel Álvares.

A afirmação de que os trabalhos tradicionais negavam a diferença entre as línguas ganha corpo no século XX, com o estruturalismo. Ao enfatizar a diferença entre as línguas, a ponto de defender que elas "podem diferir entre si sem limites e de modos imprevisíveis" (JOOS, 1957 [1966], p. 96), o estruturalismo do século XX transformaria a filiação de uma gramática a algum modelo latino na pedra de toque para aferir a qualidade das descrições tradicionais em geral. A partir de então, a essas obras do passado seria aplicado o leitmotiv de que teriam seguido idéias preconcebidas e que se restringiram a transpor categorias do latim para outras línguas, não percebendo sequer as diferenças existentes. Leonard Bloomfield (1887-1949), por exemplo, talvez o maior nome do estruturalismo norte-americano, afirmava que os estudiosos do século XVIII "estabeleceram os traços gramaticais de uma língua em termos filosóficos, e não levaram em conta a diferença estrutural entre as línguas, antes a obscureceram, ao forçar suas descrições no esquema da gramática latina" (BLOOMFIELD, 1933 [1984], p. 8). Mais recentemente, o lingüista sueco Bertil Malmberg (1913-1994), ao tratar do contacto dos europeus com as línguas americanas no século XVI, reforçava a mesma visão, ao afirmar que

[a] gramática da língua indígena seguia, segundo eles [esses gramáticos-mcr], o modelo do latim (do espanhol e do português). Procuravam-se todos os tipos de correspondências com categorias bem conhecidas de nossas línguas, a fim de concretizar os mesmos paradigmas, sem que o gramático se desse conta da ausência dessas categorias, nem da presença de outras, na língua a descrever. (MALMBERG, 1991, p. 181)

Esse tipo de crítica aos trabalhos gramaticais do passado tem muito de incompreensão historiográfica. Como nota Haastrup (1990, p. 96), duas razões levaram estudiosos do passado a descrever os vernáculos com as categorias latinas. Primeiramente, a semelhança com o latim conferia prestígio a uma língua. Em segundo lugar -e 
mais importante - o "latim não era considerado apenas a gramática de uma língua, mas o mais próximo que se poderia chegar de uma gramática universal". Afora a incompreensão historiográfica, a proposta de que todas as línguas são semelhantes ao latim, do ponto de vista do critério popperiano da falsibilidade das hipóteses, é mais interessante do que a proposta estruturalista de que todas são diferentes do latim, uma vez que é suficiente precisar o predicado "semelhante ao latim" para torná-la falsa (BACH, 1965 [1973], p. 16).

Justifica-se a seleção de obras para análise. A opção por trabalhos da Companhia de Jesus se deu em virtude não só do empenho que essa Ordem aplicou à descrição de línguas, por conta de suas Constituições, como também pela quantidade de documentação existente sobre as propostas que seguiram. Procurou-se estabelecer um conjunto de obras que estivessem temporalmente próximas, para que eventuais mudanças programáticas não viessem a afetar o material a ser comparado - e esse conjunto ficou, temporalmente, em torno da segunda metade de Seiscentos. Cada uma das três é a primeira gramática de um ocidental sobre aquela língua. A seleção contempla ainda um outro aspecto: a atitude em relação a línguas até então desconhecidas com e sem escrita: os trabalhos focalizados descreveram duas línguas ágrafas (dois vernáculos, portanto) e uma com séculos de tradição escrita (uma língua-padrão, por conseguinte).

As seções que se seguem focalizam, primeiramente, a letra; em seguida, a palavra e a construção, em acordo com as partes da gramática na tradição greco-latina. A letra é o elemento primitivo de uma hierarquia formada por quatro unidades. A letra forma a sílaba, que forma a palavra, que forma a sentença:

Syllaba fit ex literis vna, vel pluribus, vt A, le, as. Syllaba, quæ fit ex duabus vocalibus vocatur DIPHTHONGUS. Diphthongi sunt sex, æ, au, ei, eu, œ, yi, vt Præmium, aurum, omneis, Europa, pœna, Harpyia. Dictio fit ex syllabis, Aleas: interdum fit ex vna syllaba, vt Mors.Oratio fit ex dictionibus, vt Aleas fuge. Mortem meditare.

['A sílaba é composta de letras, uma ou mais, assim: $A$, le, as. A sílaba composta por duas vogais se chama ditongo. Os ditongos são seis: æ, au, ei, eu, œ, yi, assim: Præmium, aurum, omneis, Europa, poena, 
Harpyia. A palavra é composta de sílabas, Aleas; algumas vezes é composta de uma sílaba, assim: Mors. A sentença é composta por palavras, assim: Evita o acaso, Meditar na morte. - Álvares, 1572, p. 46.]

Essas unidades constituem-se nos elementos nucleares das quatro partes da gramática: respectivamente, a ortografia, a prosódia, a etimologia e a construção.

\section{MATERIAIS E MÉTODO}

\subsection{O corpus}

Todas as obras aqui focalizadas descreveram uma língua que era estrangeira para seus autores e para seu público-alvo. São elas a Arte de grammatica da lingua de Angola, ${ }^{1}$ do jesuíta português Pedro Dias (?-1700), Reitor do Colégio de Olinda, publicada em Lisboa em 1697, por Miguel Deslandes; a Arte de grammatica da lingua brasilica da Naçam kiriri, ${ }^{2}$ de Ludovico Vincenzo Mamiani della Rovere (1652-1730), impressa em Lisboa em 1699, também por Miguel Deslandes; e a Grammatica Linguae Sanscretanae Brachmanum India Orientalis, ${ }^{3}$ inédita, escrita por volta de 1660-1662, pelo alemão Heinrich Roth (1620-1668), Superior do Colégio Jesuíta de Agrá.

A Arte da lingua de Angola descreve o quimbundo, ou luanda, ou ndongo, língua nigero-congolesa do subgrupo banto, uma das muitas línguas bantas ainda hoje faladas em território angolano (vide GRIMES, 1996, p. 160-164). Escrita no Brasil, a Arte teve uso entre os missionários que recebiam os navios negreiros vindos da África. É o primeiro trabalho gramatical sobre essa língua, que voltaria a receber atenção somente em fins do século XIX (DOKE \& COLE, 1961, p. 20), com o trabalho do suíço Heli Chatelain (1859-1908)4 e com o do português Henrique de Carvalho. ${ }^{5}$ A gramática de Dias foi antecedida em 55 anos do catecismo nessa língua do também jesuíta Pe. Francesco Pacconio (1589-1641), a que Dias se refere por duas vezes (DIAS, 1697, p. 9; 34). Pacconio não escreveu uma gramática mas, por ser o pioneiro no registro do quimbundo, fez anteceder seu catecismo de 
um prólogo de Advertencias para se ler a lingua de Angola, que muito facilita a compreensão do texto de Dias no tocante à ortografia.

A Arte de grammatica da lingua brasilica da Naçam kiriri, do Pe. Mamiani, registrou o dialeto quipeá do quiriri. Várias foram as classificações já propostas para o quiriri (vide AZEVEDO, 1965; RODRIGUES, 1986 [1994]), que foi falado na região em que se situam atualmente o estado de Sergipe e o noroeste da Bahia (RODRIGUES, 1986, p. 49), mas que está extinto.

A Grammatica Linguae Sanscretanae Brachmanum India Orientalis, do Pe. Roth, nunca chegou a ser impressa. ${ }^{6}$ Descreve o sânscrito, língua indo-européia do ramo índico. Embora haja estudos sobre o sânscrito pelo menos desde o século IV a.C. (CARDONA, 1990, p. 26), a Grammatica de Roth constitui-se na primeira descrição do sânscrito feita por um europeu.

Há, porém, alguns aspectos que diferenciam esses trabalhos. Primeiramente, a Arte de Dias e a Arte de Mamiani estão escritas em português; a exemplificação, em geral traduzida, se faz em caracteres latinos. A nomenclatura gramatical é aquela da tradição latina. A gramática de Roth, por seu turno, nem trata de um vernáculo nem está escrita em vernáculo, mas em latim. Não é em transliteração latina que a exemplificação é apresentada por Roth ao leitor: toda a exemplificação se faz em devanágari. ${ }^{7}$ Aquele disposto a estudar a obra de Roth defronta-se, porém, com um segundo obstáculo para além da grafia: a nomenclatura gramatical empregada pertence a um tradição do Oriente. Para alguém formado na tradição greco-latina, o trabalho de Roth apresenta terminologia desconhecida, como anusvāra, anunāsika, visarga, var?a ... Por fim, um outro aspecto, já no título, agrupa as obras de Mamiani para o quiriri e de Dias para o quimbundo de um lado e, de outro, a de Roth para o sânscrito. Ao passo que as duas primeiras receberam a denominação arte, que as reveste de carácter de regras dissociadas dos auctores ( $v$. CURTIUS, 1948 [1996], especialmente, 283ss, 585ss), a obra de Roth não é designada por arte, mas por grammatica. A denominação gramática (CURTIUS, 1948 [1996], p. 534) remete o leitor à divisão bipartite em estudo do bem falar e interpretação dos poetas a par com a composição 
escrita. No caso do sânscrito, a tradição greco-latina entrava em contacto com uma outra tradição gramatical igualmente antiga.

\subsection{Manuel Álvares como modelo descritivo}

Segundo Verdelho (1995, p. 133, n. 111),

em 1558 já os Jesuítas consideravam a necessidade de escrever uma gramática não só de latim, mas também de grego e de hebraico, e em 1564, o Geral da Companhia, Diogo Laines, "constando-lhe que o P. Manuel Álvares tinha escrito sobre gramática "algumas cousas que podiam ser muito proveitosas ao bem comum", pediu-lhe que lhas enviasse, para as comunicar a muitos, se lhes parecesse bem".

Esses escritos constituíram, muito provavelmente, o embrião da famosa gramática de 1572 (VERDELHO, 1995, p. 121), que conheceria mais de 500 edições (VERDELHO, 1995, p. 47, n.8) e que seria a gramática latina por excelência até o século XIX. A gramática de Manuel Álvares, inicialmente, viria a substituir a gramática do flamengo Johannes Despauterius (1460-1520), adotada nos colégios da Ordem em Portugal entre 1555 e 1572 (VERDELHO, 1995, p. 100101). A obra de Álvares seria expressamente recomendada para o ensino regular de latim em todos os colégios da Ordem no Ratio Studiorum de 1599:

23. Gramática do P. Álvares - que os nossos professores adotem a gramática do P. Manuel. Se em algum lugar o seu método parecer muito elevado para a capacidade dos alunos, adote então a gramática romana, ou após consulta do Geral, mande compor outra semelhante, conservando sempre, porém, a importância e propriedade de todas as regras do P. Álvares (Ratio studiorum, Regras do Provincial - in Franca, 1952, p. 128).

A gramática latina de Álvares é composta por três partes, ou livros, cada uma dedicada a uma das séries dos estudos inferiores: a etimologia, a sintaxe e a prosódia. ${ }^{8}$ Toda a apresentação está centrada na palavra e em suas flexões. Mesmo a construção (ou sintaxe) é apresentada por classe gramatical. 
A primeira parte da gramática de Álvares tem início pelas declinações do nome e do verbo (fo. $1^{\text {reto }}-45^{\text {verso }}$ ) e continua com os Rudimenta, ${ }^{9}$ siue de octo partibus Orationis ( $\left.46^{\text {recto }}-107^{\text {verso }}\right)$. O livro II, De octo partium orationis constructione $\left(108^{\text {recto }}-195^{\text {recto }}\right)^{10}$ focaliza a sintaxe das diferentes classes e termina com as figuras de sintaxe. O terceiro livro (fo. $196^{\text {verso }}-244^{\text {verso }}$ ) trata da sílaba (De syllabarum dimensione).

Nos estudos aqui focalizados, a representação gráfica ocupa a parte inicial dos textos. Em Álvares (1572, p. 46), os rudimentos têm início pelas letras:

LITER $Æ$, quibus vtuntur Latini sunt tres \& viginti, A, Be, Ce, De, E, Ef, Ge, Ha, I, Kappa, El, Em, En, O, Pe, Qu, Er, Es, Te, V, Ix, Y psilon, Zeta. Literæ diuiduntur in vocales, \& consonantes. Vocales sunt sex, A, E, I, O, V, Ypsillon, quarum vltima tantum in dictionibus Græcis locum habet, vt Hieronymus, Dionysius. Cæteræ appellantur consonantes, quòd vocalibus iunctæ simul sonent.

['As letras de que se faz uso em latim são 23: $a$, bê, cê, dê, efe, gê, agá, $i$, capa, ele, eme, ene, o, pê, quê, erre, esse, tê, vê, xis, ipsilon, zê. As letras dividem-se em vogais e consoantes. As vogais são seis: $A$, $E, I, O, V, Y p s i l o n$, porque esta última somente tem lugar em palavras gregas, assim: Hieronymus, Dionysius. Todas mais são denominadas consoantes, que soam juntas às vogais ao mesmo tempo.']

Nas páginas seguintes, Álvares explica as propriedades ou atributos das letras: nomen, figura, potestas, cognatio o ordo. O nome é aquele pelo qual a letra é denominada: as vogais, por exemplo, são denominadas pelo modo como se escrevem (ÁLVARES, 1572, 46 verso). Figura é a forma pela qual se escreve. Potestas é o valor da letra: $<\mathrm{v}>$ pode ser consoante ou vogal, na dependência do elemento com que co-ocorre. Cognatio denomina o tipo de relação que abrange a distribuição de letras: $<\mathrm{m}>$ e $<$ n $>$ são empregados na dependência de estarem ou não antes de $<\mathrm{p}>\mathrm{e}<\mathrm{b}>$. Ordo trata da disposição na sílaba. A matéria continua com a definição de vogal, que tem som por ela própria (Vocales per se sonant). As consoantes são aquelas que soam em conjunto com as vogais: as semivogais, as consoantes pronunciáveis em isolado como as vogais, $<\mathrm{f}, \mathrm{l}, \mathrm{m}, \mathrm{n}, \mathrm{r}, \mathrm{s}, \mathrm{l}>$; a 
consoante dupla $<\mathrm{x}>$, que Alvares denomina $i x$; e as mudas, que não podem ser pronunciadas sozinhas ("quòd per se sine adminiculo vocalium non possunt enuntiari" - Alvares, 1572, $46^{\text {verso }}$ ), <b, c, d, $\mathrm{g}, \mathrm{k}, \mathrm{p}, \mathrm{q}, \mathrm{t}>$. O texto prossegue com a discussão de letras específicas: $<\mathrm{h}>$, se seria uma letra ou um grande espírito diante de outra letra, a indicar a aspiração; e, em seguida, o uso de $<\mathrm{c}>,<\mathrm{k}>\mathrm{e}<\mathrm{q}>$.

A Institutione Latina de Álvares descrevia o latim, uma das três línguas consideradas sagradas. Seu estudo, por conseguinte, não necessitava de justificativas. No âmbito da Companhia de Jesus, seu ensino regular se fazia nos colégios, com o objetivo de alcançar a eloquentia perfecta, ou "o uso correto da razão aliada à expressão cultivada” (Ó MATHÚNA, 1986, p. 137). As artes, por seu turno, não se destinavam ao mesmo público, porque estavam voltadas para o ensino de línguas estrangeiras a membros da Companhia de Jesus em missão de conversão de novos povos, "em particular aos que moraõ entre Gentios, EBarbaros" (MAMIANI, 1699, fol. ii). Essa era a razão de tal empresa: "naõ julguem estudo indigno dos annos aprender de novo linguas barbaras, quando saõ necessarias para a conversaõ das almas" (MAMIANI, 1699, fol. ii ${ }^{\mathrm{v}}$-iii). Não fosse a necessidade de "trattar de suas almas" (id. et ibid.), aprender uma língua bárbara pareceria "tempo perdido" e "occupação escusada" (id. et ibid.). Além disso, as peculiaridades culturais dessas populações eram vistas como uma dificuldade a mais na tarefa de reduzir a arte tais línguas: "He verdade que como os naturaes vivem sem regras, E sem ley, E delles se naõ póde alcançar regra algua de raiz, naõ parecia tã̃ facil poder acertar sem Mestre" (MAMIANI, 1699, fol. iiiv-iv).

Para descrever as novas línguas, os missionários contavam, em princípio, com o alfabeto latino, que já recebera adaptações para servir aos vernáculos europeus. Decidida a representação de cada som, apresentava-se a questão de como descrever a gramática. A referência para todos da Companhia era a obra de Álvares, um modelo gramatical centrado na palavra e em suas variações morfossintáticas. As diferenças entre as línguas eram percebidas, mas o problema era o modo como referir essas diferenças. 


\section{RESULTADOS}

\subsection{O estudos das letras e sons}

No que diz respeito às línguas ágrafas, aqueles que levaram a cabo a tarefa de descrevê-las esforçaram-se em fazer com que o alfabeto latino, recurso de que dispunham, representasse não apenas os sons existentes em latim, mas também sons que eram alheios ao latim. A tarefa não era fácil, porque o ideal de um repertório de símbolos comuns de leitura única e inequívoca esbarrava nos novos contrastes com que se deparavam nessas línguas até então desconhecidas no Ocidente. Veja-se, a título de exemplo, numa solução que se reporta à tradição gráfica medieval de não considerar $<\mathrm{i}>\mathrm{e}<\mathrm{j}>$ caracteres com valores distintos, a proposta de Mamiani (1699, p. 3-4) para representar as vogais alta fechada anterior não-arredondada e alta fechada central não-arredondada, respectivamente [i] e [1] , mas também para a representação de o que parece ser a africada $\left[d_{3}\right](e$ não a fricativa pós-alveolar sonora [3]):

I, nesta lingua tem quatro vocalidades, duas de vogal, \& duas de consoante. A primeira he de I vogal como no Portuguez: a segunda de consoante, como tambem no Portuguez nestas palavras, Jogo, Janella; mas com som mais brando, v.g. Adje, quem; Udje, que. A terceira he de I, tambem vogal guttural, a que os Authores da arte da lingua gèral do Brasil chamáraõ I grosso, pois se acha tambem nessa lingua: \& assim como elles o escrevem por Y, para o differençar do I vogal simplex, tambem nós o escrevemos com o mesmo caracter, porèm com accento circunflexo por cima, assim, $\hat{y}$, para o differençar de outro $Y$ consoante, que se escreve sem acento.Pronuncia-se pois esta vogal como I, guttural, \& na garganta com os dentes fechados; v. g. M ŷgh ŷ, contas; P ŷ, capim. A quarta vocalidade, ou som do I, he de I carregado, ou consoante duplex, como usaõ os Castelhanos na syllaba yo; \& se introduzio tambem na escritura Portugueza, como nestas palavras, Mayor, Cayar: \& por isso a escrevemos tambem nesta lingua por Y sem accento, v. g. Buỹe, grande; Cayà, noite. 
Na tentativa de manter o mesmo símbolo já empregado para a vogal alta central [t] e diante da necessidade de distingui-lo da vogal assilábica, Mamiani recorre a um diacrítico, criando, de qualquer modo, um novo símbolo. O carácter experimental de soluções gráficas propostas para os sons desconhecidos presentes nessas línguas fez os gramáticos recorrerem aos inventários de grafias de que tivessem conhecimento e que pudessem servir de solução para o problema que tinham, como no exemplo a seguir, extraído de Mamiani (1699, p. 2)

O C sempre se pronuncía aspero assim sobre as vogaes A, O, U como sobre E, I, Y. E porque nestas derradeiras vogaes o C fere brandamente no Portuguez; para evitar o erro que poderia haver escrevendo-se o C com ella, se introduzio o K, caracter Grego, que sempre tem o som aspero sobre todas as vogaes: v.g. Kempe, fino; Kitçi, area.

As dificuldades dos missionários não teriam sido estranhas aos primeiros que começaram a escrever nos vernáculos europeus, para quem a escrita latina fora objeto de várias tentativas de adaptação. A evolução dos grupos latinos iniciais $\langle$ pl $>,<\mathrm{cl}>$ e $<\mathrm{fl}>$, por exemplo, resultou em $<\mathrm{ch}>$ no galego-português, onde representava [ť̌s, e em $<$ ll> em castelhano, onde representava [K]: lat. plenu-; gal.-port. cheo; cast. lleno.

Havia, porém, outros problemas tanto para o gramático incumbido de descrever essas línguas como para seu leitor. Se a grafia do latim estava razoavelmente estabelecida, sua pronúncia variava. Como nota Burke (1991, p. 41), após 1500 é necessário levar em conta os vários domínios lingüísticos para o latim, entre eles os diferentes tipos de usuários. Não se espera do latim clerical, por exemplo, a pronúncia reconstituída prescrita por eruditos do Renascimento, encabeçados por Erasmo (1466?-1536). ${ }^{11}$ Leve-se em conta que mesmo num ambiente de intelectuais como a Universidade de Cambridge, a introdução da proposta de Erasmo criou condições para uma disputa entre seus partidários e aqueles que defendiam a pronúncia tradicional do latim (e também do grego) na Inglaterra em que, por exemplo, $<\mathrm{s}>$ intervocálico e $<\mathrm{g}>$ latinos recebiam, 
respectivamente, as pronúncias [z] e [j]. A disputa resultou num édito de 1542, de efeito temporário, é certo, que proibia as novas pronúncias reformadas para o latim e também para o grego (ALLEN, 1978, p. 102110). Tentativas de alterar pronúncias tradicionais do latim na França - como [tãpys] para o latim tempus, [kãkã] para o latim quamquam ou [nilill para o latim nichil - esbarraram em fortes reações dos teólogos da Sorbonne, a ponto de serem consideradas "heresias gramaticais" (ALLEN, 1978, p. 106-107).

O produto de tantas pronúncias locais para o latim somado a diversas tentativas de fixação de pronúncias reformadas levou ao paradoxo de ter-se uma língua de comunicação internacional que nem sempre podia ser compreendida se empregada fora da terra natal daquele que a falava. No início do século XVII, por exemplo, o erudito francês Joseph Scaliger (1540-1609) dizia do latim de um visitante inglês que "neque ego magis eum intelligerem, quam si Turcice loquutus fuisset" ('nem eu o compreendia mais do que se falasse em turco' - Apud ALLEN, 1978, p. 10; vários outros exemplos em BURKE, 1991, p. 59-60).

Resulta desse contexto que nem sempre são claras algumas afirmações em que são comparadas a fonética de um vernáculo à fonética do latim, porque ainda se soma a esse quadro já complexo a nem sempre clara distinção entre um som e sua representação. Um exemplo: ao descrever o quimbundo, Dias (1697, p.1) informa que:

[o] Pronunciar, \& escrever he como na lingua Latina, com advertencia que naõ tem $\mathrm{R}$ dobrado, nem no principio do nome, nem no meyo, v.g. Rierino, hoje: Rimi, lingua.

Podemos ter duas interpretações para " $r$ dobrado": (a) a informação de que nessa língua não havia a oposição do português entre as vibrantes apicais múltipla e simples; ${ }^{12}$ ou (b) a informação meramente gráfica de que não havia razão para escrever, nessa língua, rrierrino, por exemplo com <rr> inicial ou medial. A dúvida sobre o conteúdo da afirmação de Dias desfaz-se com a consulta ao catecismo do Pe. Pacconio que, numa das dez Advertencias, comparou a pronúncia do $<\mathrm{r}>$ do quimbundo com a do português com 
exemplificação que não deixava margem para dúvidas (PACCONIO,

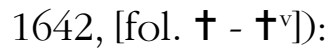

3. Nunca dobram a letra, R, ou seja, no principio do nome, ou no meyo. Exemplo, Ririmi. lingua, Ritui, orelha, Rigi< $<. .>$ buluilo, declaraçam: por onde se se achar nome, que comece por, R, não se dobrarà tal letra, mas pronunciarseà como a penultima de marisco marinho, \&c.

A falta de clareza na distinção entre som e letra, aliada ao carácter rudimentar do alfabeto latino como instrumento para a descrição fonética faz com que, por exemplo, toda a seqüência de plosivas e de fricativas pré-nasalizadas seja apresentada com a ligeireza de um detalhe gráfico: "As letras seguintes, B, D, G, V, Z, se lhe poem antes a letra N, v.g. Nburi, Carneiro, Ndungue, Traças, Ngombe, Boy, Nvula, Chuva, Nzambi, Deos”. Nesse caso, novamente a conjugação da gramática com o catecismo pode valer de ajuda ao leitor e, mais uma vez, não é ao latim (ou mesmo a uma língua européia) que o autor recorre, mas a uma língua do Novo Mundo que apresentava esse som pouco conhecido:

4. De ordinario os nomes, ou verbos que começam nestas letras, B.D, G, V. consoante, \& Z. se lhes poem hũa letra N, antes porque na pronunciaçam mostram, que requerem este N. [...] E também na lingua do Brasil se acha esta pronunciaçaõ. Exemplo. Nde, id est Tu. Ndaeteè, por isso eu. (PACCONIO, 1642, [fo. $\left.{ }^{\mathrm{v}}\right]$ ).

Com a procedência variada dos missionários da Ordem, podiam apresentar-se comparações entre, de um lado, a fonética da língua em estudo e a escrita para ela proposta e, de outro, o valor de determinada letra no sistema gráfico de alguma língua européia.

Quando o vocabulo acaba em A, ou $Æ$ sem accento, \& sem til, se pronuncîa essa vogal a meya boca mal pronunciada como E Francez no fim da palavra: v.g. Pide, està; Tekiébæ, naõ veyo. (MAMIANI, 1699, p. 5).

A clareza que esses gramáticos tiveram sobre a influência que a maior familiaridade com um dos vernáculos europeus poderia ter 
sobre a grafia proposta ficou registrada. É o caso, por exemplo, do Catecismo Brasílico na edição de 1686, que reviu a edição de 1618 (ênfase acrescentada):

\section{Adveatencia [sic] sobre a ortographia, \& pronunciaçaõ deste Catecismo.}

Este Catecismo como produzido pelos Portuguezes, he Portuguez na escritura; que pode admitir a penna Portugueza.

E assi se usa nelle Ç com zeura ${ }^{13}$ em lugar do S, cujo natural sibilo naõ consente a lingoa Brasilica. Escrevese Nha, nhe, \&c. para formar aquela voz, que se profere nas ultimas syllabas destas nossas palavras, Tenha, Tenho. [....]

Por seu turno, a escrita dos vernáculos europeus não estava ainda padronizada, o que dava margem a variação. O confronto entre as grafias portuguesas empregadas nas obras de Dias e de Mamiani, por exemplo, chama a atenção pelas diferenças, em especial no tocante ao uso de diacríticos, embora fossem ambas saídas da mesma oficina de Miguel Deslandes no espaço de apenas dois anos. Assim, o que seria uma fórmula prática para evitar erros na pronúncia podia, ao final de contas, não sê-lo. Como seria, por exemplo, a pronúncia de quu no português, como na comparação presente no excerto a seguir?

As syllabas, qua, que, qui, quo, quu, pronunciaõ-se como no Portuguez, v.g. Guiria, como. E assim saõ as seguintes, ga, gue, gui, go, gu. ja, je,ji, jo,ju. ya, ye, yi, yo, yu. (DIAS, 1697, p. 1-2).

Em princípio, seria um equivalente da grafia $<\mathrm{cu}>$, mais comum no português mesmo nessa época. ${ }^{14}$ Em outras palavras: a preocupação em tornar claro o referente sonoro de determinada representação gráfica com o recurso a um uso em dado vernáculo esbarrava na ausência de fixação ortográfica também para os vernáculos.

O carácter experimental das soluções gráficas propostas tornase mais evidente quando edições diferentes da mesma obra, ou obras diferentes sobre a mesma língua são postas em confronto. Mudam os diacríticos empregados. E pode-se perguntar se, por vezes, isso teria acontecido na dependência de um fator extralingüístico, como 
a disponibilidade de tipos da casa impressora. Pode ser essa a razão que redundou na diferença entre o mesmo exemplo em Pacconio ${ }^{15}$ e em Dias, a seguir:

8 Esta lingua de Angola faz em muitos nomes synalepha, como a latina, \& Italiana, mas muitas vezes a nam faço aonde se podem deixar sem erro: tirado onde seria erro, \& nota nam se fazer synalepha. Exemplo. macamba ami, se faz synalepha. Macamb'ami, meus amigos. Mona üetu, Mon'etu, nosso filho, \&c. (PACCONIO, 1642, †v- †† - ênfase acrescentada).

Fazem frequentemente sinalefas algus nomes, quando se ajunta o adjetivo ao sustantivo, \& perdem muitas vezes duas, \& mais letras, v.g. Macambaami, meus amigos, dizem Macambàmi. Mubicauàmi, dizem, Mubicàmi, meu escravo. (DIAS, 1697, p. 2 ênfase acrescentada)

Numa arte não havia necessidade de se apresentarem as propriedades da letra, porque, sendo parte dos fundamentos, valeriam para todas as línguas; havia necessidade de se particularizar o inventário específico da língua em análise, e o instrumento para isso, o alfabeto latino, dava margem a todas as questões aqui apontadas. Uma língua ágrafa do Novo Mundo, contudo, não passava a ser língua escrita mesmo ao receber registro escrito no contexto em que esses missionários escreveram e em que tiveram de justificar a escolha do objeto de estudo e até de decidir se estavam ou não perante uma língua passível de ser descrita em regras: permanecia uma língua oral, como Anchieta (1595, p. 9 - ênfase adicionada) ressaltaria:

Isto das letras, orthographia, pronunciação, \& accento, seruira pera saberem pronunciar, o que acharem escrito, os que começão aprender: mas como a lingoa do Brasil não está em escrito, senão no continuo vso do falar, o mesmo vso, \& viua vOZ ensinaram melhor as muitas variedades que tem, porque no escreuer, \& accentuar cada hum farâ como lhe melhor parecer.

Nas obras sobre o quimbundo e o quiriri reconhece-se que a escrita se constitui no meio de acesso à língua fora do ambiente em 
que é falada, mas que se está diante de uma aproximação apenas, cujas lacunas devem ser preenchidas com o uso efetivo da língua na comunidade de destino do missionário. Nas palavras de Mamiani (1699, fol. $\mathrm{iii}^{\mathrm{v}}$ - iiij - ênfase acrescentada), por exemplo:

Mas contudo procurei com o exercicio de algus annos da mesma lingua, \& com o estudo particular della, tirar os fundamentos, \& regras mais certas, para que com ellas se formasse hua Arte facil, \& clara, quanto bastasse para os nossos Missionarios das Aldeas dos Kiriris aprenderem a lingua. Naõ duvido que faltaráõ algumas propriedades mais secretas, \& alguas regras mais reconditas, que naõ se puderã̃ ainda alcançar; mas pareceme que nas regras geraes, que aqui se apontaõ, não haverá erro.[....] com todas as suas imperfeiço?s sempre será proveitosa para quem quizer usar della, em quanto não houver outra melhor, \& composta com todo o acerto.

Afinal, tais línguas não tinham existência escrita e, por conseguinte, não contavam com auctores. Uma arte era o bastante. Não era essa a situação na Ásia. Francisco Xavier, em carta a Inácio de Loyola, datada de 14 de janeiro de 1549, registrou sua perplexidade com a escrita japonesa (Apud LACOUTURE, 1991, p. 144):

Eles escrevem de um modo muito diferente de nós, de cima para baixo. Perguntei a Paulo ${ }^{16}$ por que não escreviam à nossa maneira, ele me retrucou por que não escrevíamos nós à maneira deles. E me deu como razão que assim como o homem tem a cabeça no ar e os pés em baixo, quando escreve, o homem deve (fazêlo) de cima abaixo.

Após os fracassos iniciais de Francisco Xavier na Índia, a Companhia de Jesus passaria a admitir a necessidade de conhecimento das culturas em que procurava exercer a missionação. Passaria também a admitir uma "sinização" ou "indianização" da fé cristã (DIDIER, 1996, p. 41; PIERRARD, 1991, p. 225), consoante seus missionários estivessem na China ou no Hindustão. Diferentemente das línguas necessárias à missionação em culturas ágrafas, para as quais a adaptação do alfabeto latino se punha como a única hipótese a ser considerada, línguas com tradição escrita diversa da latina permitiam ao menos a possibilidade 
de duas abordagens: em caracteres locais ou em sua transliteração latina. A influência de um fator extralingüístico na opção pela grafia não-latina tem de ser levada em conta para a região para onde Roth fora enviado: a tentativa de retirar dos missionários e da Igreja o rótulo pejorativo de parangi, e a suspeita dos brâmanes de que o batismo os conduziria à perda de títulos, nobreza e casta. ${ }^{17}$

$\mathrm{Na}$ Ásia, a Companhia de Jesus estabeleceu oficinas tipográficas ainda em 1556, caso de Goa. Tanto quanto possível, forjaram-se tipos para os caracteres locais: em 1577 o Ir. João Gonçalves montava uma oficina em Vaipicotta, com tipos para o malaiala; em 1578, Fr. João de Faria moldaria os tipos para o tâmil, para uma oficina em Punicalé (ALMEIDA, 1992, p. 199). Por sua vez, Tomás Estêvão, autor de uma gramática para o concani, a Arte de Lingoa Canarim, teria de se contentar com o alfabeto latino e adaptá-lo, porque

cousa sabida he. que todas as lingoas de Europa se escreuem com 24 letras pouco mais ou menos. Mas nestas terras, como os characteres naõ saõ letras, senaõ syllabas que resultaõ das combinaçoẽs das vogais \& consoantes do nosso Alphabeto. De modo que por 24 elementos, que nos temos, teraõ elles pouco menos de sete centos. Por onde se ouue por escuzado trazellos neste tratado, por rezaõ da multidaõ delles. E tambem porque os que sabem nossa letra mais facilmente escreuem. \& leem por ella do que costumaõ os escriuais da terra polla sua. Todo o negocio consiste em saber quaes saõ as nossas letras que podem responder as desta terra, satisfazendo com ellas a orthografia, \& aos accentos, \& pronunciaçaõ. Porque os Indios tem encerradas em seus characteres muitas letras, que nos naõ temos em nossa Europa. E pera as declarar com nossas letras somos forçados de nos ajudarmos de accentos, \& letras dobradas, \& aspiraçoẽs, \& com as regras que ao diante se veraõ. (ESTÊVÃO, 1640, fol. A-Av).

No caso da Índia, a par com as razões levantadas por Estêvão, razões econômicas dificultariam o registro impresso de línguas em caracteres locais, talvez a razão para o trabalho de Roth ter permanecido manuscrito. O sânscrito conta com 47 símbolos para consoantes e vogais (RENOU, 1984, p. 2); ${ }^{18}$ apresenta, no entanto, levando-se em conta apenas as ligaturas mais comuns, outros 221 sinais. 
O estudo do sânscrito não se fez no alfabeto latino, mas numa escrita local, o devanágari. O traço horizontal sobre os símbolos que cria contínuos na escrita constitui a característica marcante dessa escrita, que combina características de alfabeto - na medida em que cada fonema tem um sinal para representá-lo -, com características de silabário, uma vez que a sillaba tem notação por meio "de um único grupamento gráfico, em que o elemento consonântico constitui a parte essencial, ficando o elemento vocálico por assim dizer aí acrescido " (RENOU, 1984, p. 2). O devanágari, diferentemente da escrita em caracteres latinos, tem traçado pleno para as vogais quando escritas em isolado, mas uma forma abreviada, quando estão associadas a uma consoante; quanto às consoantes, grupos consonânticos tornam-se ligaturas.

Roth faz a apresentação inicial dos símbolos ser acompanhada de sua transliteração latina, o que não facilita em muito a tarefa do leitor. A transliteração latina de Roth é plena de consoantes dobradas com diacríticos incomuns sobre elas e aspirações, como <đđahă $>$. As transliterações das consoantes do devanágari seguem a tradição de sempre as apresentar seguidas de um $<\breve{a}>$, porque, quando em isolado, as consoantes são pronunciadas como se todas fossem seguidas de $a$ breve. Também a ordem de apresentação dos símbolos não é semelhante à ordem alfabética latina. Roth apresenta os caracteres em grupos: primeiramente as vogais (transliteradas como $a, i, u$, ree lre, sem a seqüência de longas), em seguida as semivogais (transliteradas como $b^{T M}, i^{T M}, u^{T M}, r^{T M}$ e $l^{T M}$ ) e mais seis grupos de cinco consoantes cada, e um último, de três. Ao missionário que quisesse estudar sânscrito pela obra de Roth, não bastaria, porém, além de aprender uma escrita em caracteres não latinos, saber gramática latina - exigência referida por Anchieta numa carta a seus colegas de Ordem. ${ }^{19}$ Era necessário ainda conjugar o conhecimento da nova escrita ao conhecimento de uma outra tradição gramatical.

\subsection{O estudo das classes gramaticais e da construção}

Após a parte dedicada à pronúncia das letras, as obras introduzem o leitor no estudo das declinações. As diferenças entre 
o latim e essas línguas são claras, no caso de Mamiani e de Dias. Alguns exemplos se seguem:

OS Nomes nesta lingua naõ tem propriamente distinçaõ de generos, ou numeros, ou casos, mas o mesmo nome sem mudança serve de ordinario ao genero masculino, \& feminino, ao numero singular, \& plural, \& em todos os casos: verbi gratia. este nome Cradzó, significa Vacca, \& Boy, masculino, \& feminino, \& sem variaçaõ serve ao singular, \& plural, \& do mesmo modo serve a todos os casos. Bihè cradzò, hua vacca, ou boy no singular; Buyò cradzò, muitas vaccas no plural (MAMIANI, 1699, p. 6-7)

Os casos se conhecem ou pela collocação do nome, ou pelas preposiçoens. O nominativo, \& genitivo se conhece pela collocação; porque o nome, que se segue immediatamente ao verbo sem preposição, he nominativo; ut, Sucá inhuræ do diapadzù, o filho ama a seu pay : \& o nome que for immediatamente depois de outro nome sem ter preposiçaõ, he genitivo; ut, Erà Tupã, casa de Deos. Os outros casos todos se conhecem pelas preposiçoens, porque nesta lingua naõ ha caso algum sem preposiçaõ fóra do Nominativo, \& genitivo, como se entenderá melhor, quando tratarmos das Preposiçoens. (MAMIANI, 1699, p. 8-9)

Naõ tem esta lingua declinações, nem casos: mas tem sigular, \& plurar, verbi gratia. Nzambi, Deos. Gimzambi, Deoses. (DIAS, 1697, p. 4)

Dias prossegue com as classes nominais do quimbundo, marcadas pelos prefixos de singular e de plural, características das línguas bantas: "Regras para saber o plurar pelo singular, \& para adjectivar o sustantivo com o adjectivo no singular, \& plurar".

Em maior ou menor grau, as regras apresentadas nas descrições de Dias e de Mamiani pressupõem um leitor para quem o texto de Manuel Álvares fosse familiar. Em relação à obra de Dias, a familiaridade permitiu prescindir do enunciado completo de cada regra. Assim, por exemplo, em Dias (1697, p. 33-34), a descrição da sintaxe tem início como apresentado no Quadro 1 a seguir, em que se referem as regras da sintaxe de Álvares de forma abreviada, indicada pelo símbolo para et coetera: 


\section{QUADRO 1}

As três primeiras regras da sintaxe em Álvares e em Dias

\begin{tabular}{l} 
MANUEL ÁLVARES \\
(1572, p. $108-108{ }^{\text {verso }}$ ) \\
\hline Verbum personale finiti modi antecedit \\
nominatiuus apertè, vel occulté \\
eiusdem numeri, É persone. \\
[O verbo pessoal do modo finito pede antes \\
de si nominativo posto claramente na oração, \\
ou entendido nela escondidamente, o qual \\
nominativo há de concordar com o seu \\
verbo em número e pessoa. $]^{\circ}$
\end{tabular}

Prima, E secunda persona ferè non explicantur, nisi cum diuersa studia significamus.

[A primeira pessoa e a segunda não se põem claramente na oração, senão quando nela significamos diversos estudos.]
Pedro Dias

(1697, p. 33-34)

Regras do Nominativo. Verbum

personale, Ec.

Todo o verbo pessoal nesta lingua tem seu nominativo claro, ou occulto. verbi gratia. Eyè üacolo, eme pê ngacolo, vòs estais bem, eu tambem estou bem. O exemplo está no pronome, // Eye, \& no pronome Eme, nominativos claros. Tambem se póde dizer: Eye ücola, nguicola pè: onde está o primeiro nominativo Eye, claro, \& no segundo verbo nguicola, occulto.

Prima, \& secunda persona, \&c.

A primeira, \& segunda pessoa poem-se claramente, quando diversas pessoas mostraõ contrarios desejos. verbi gratia. Eme ngandala culunda o milonga yâ nzambi, eye cuandala cuilunda, eu guardo os preceitos de Deos, mas tu naõ queres guardalos. O exemplo está nos dous pronomes, Eye, \& Eme, postos claramente; porque os agentes mostraõ diversos desejos; porque hum quer, \& outro naõ quer.

Aut cum plus significamus, \&c.

Tambem se diz nesta lingua mais do que significamos. verbi gratia. Eye üabeta Fula o cuaba o maxima, Tu levas ventagem a Francisco na bondade. O exemplo está no pronome Eye.

Em Roth, reconhece-se a organização latina. A obra está dividida em cinco capítulos, que se assemelham, na disposição, à ordenação da gramática latina de Manuel Álvares: De orthographia, De declinacionibus nominum, De coniugacionibus verborum, De verbalibus, De Syntaxi buius Linguae, a que se soma um Appendix ad universam grammaticam ('apêndice a toda a gramática'). 


\section{DISCUSSÃO}

Uma leitura, mesmo que superficial, das obras de Dias, Mamiani e Roth deixa claro que, em nenhum momento, as línguas que descreveram foram tornadas "iguais ao latim". Ao contrário: a percepção da existência da grande diversidade lingüística que se seguiu aos Descobrimentos constituiu o contexto que tornaria possível, já no século seguinte aos das obras aqui focalizadas, o surgimento de um catálogo como o de Lorenzo Hervás y Panduro (1735-1809). Em vários momentos de sua obra, Hervás reconhece a relevância dos testemunhos deixados nessas descrições para sua proposta de classificação das línguas. No tocante ao quiriri, por exemplo, Hervás (1800, I, 153-154) declarava sua dúvida quanto a atribuir-lhe algum parentesco:

Los kiriris, que inquietaban la capitanía de la bahía, y fuéron pacificados por el P. Juan de Barros, que con ellos despues del año 1650 formó las grandes misiones de Canabrava, de Saco, de Natuba, y de Juru. Tengo un vocabulario pequeño de la lengua kiriri, hecho por un ex-jesuita portugues; y habiendo cotejado las palabras kiriris con las de otros idiomas, he hallado solamente alguna sombra [....] de afinidad entre el kiriri y el tamanaco, que es [....] dialecto corrompidísimo de la lengua caribe. [....]

Não haveria como começar a conceber a possibilidade de uma tipologia se as línguas tivessem sido reduzidas a uma estrutura igual para todas.

\section{CONCLUSÃO}

É possível reconhecer a influência da gramática latina do Pe. Manuel Álvares nas descrições jesuítas aqui focalizadas. Isso não implica, porém, que esses missionários não se deram conta da ausência de categorias latinas nas línguas que descreveram, ou da presença de outras, como afirmou Malmberg. Ao contrário: tais obras estão plenas de evidências de que seus autores perceberam que uma 
dada categoria poderia concretizar-se de maneira diferente do latim no vernáculo de cuja descrição fora incumbido. O latim não era um molde ou forma, mas um inventário morfossintático que, conhecido de todos, parece ter sido o antepassado de um treinamento para o trabalho de campo da lingüística.

\section{NOTAS}

* Versão deste trabalho foi anteriormente apresentada no II Colóquio sobre as Linguas Gerais (UFRJ, agosto de 2001). Agradeço ao Prof. Henrique Cairus (UFRJ) a revisão das traduções do latim, e à pesquisadora Cândida Barros (MPEG), a cópia de Pacconio.

${ }^{1}$ Exemplar existente na Biblioteca Nacional do Rio de Janeiro (97, 2, 15).

${ }^{2}$ Exemplar existente na Biblioteca Nacional do Rio de Janeiro (Cofre, 2, 17).

${ }^{3}$ Exemplar existente em manuscrito de ca. 1660 na Biblioteca Nacional de Roma (Mss Orientali 171, apresentado em fac-símile por Camps \& Muller, 1988).

${ }^{4}$ Chatelain, Heli. 1888-1889. Grammatica elementar do Kimbundo ou lingua de Angola. Genebra: Typ. de Charles Schuchardt. Cabe notar que o Pe. António Moreira Basílio, em carta publicada em Baião (1946, p. 71-80), arrola uma outra obra, a do capuchinho Fr. Jacinto Brusciotto de Ventralla, Regras para mais facil inteligencia do dificil idioma do Congo, publicada em Roma em 1659, pela Typis S. C. de Propaganda Fide, que seria anterior à de Dias, mas à qual não tivemos acesso.

${ }^{5} \mathrm{Na}$ mesma carta, o Pe. António Moreira Basílio informa que a obra de Henrique de Carvalho, Método prático para falar a lingua de Luanda, publicada em Lisboa em 1890, começara a ser publicada em fascículos dois anos antes, mas Basílio classificou o trabalho como "difuso, prolixo e confuso".

${ }^{6}$ No século seguinte, outro jesuíta alemão, Jan E. Hanxleden (1689-1732), escreveria um dicionário sânscrito-português e uma gramática, que também permaneceria inédita, que seria tomada como base para a primeira gramática do sânscrito impressa no Ocidente, em 1790, escrita pelo carmelita Paulino de São Bartolomeu (AMALADASS, 1992, p. 214).

${ }^{7}$ Escrita indiana cuja época de origem não é consensual: dataria do século VII, segundo Crystal (1992), ou seria posterior ao século XI, para Calvet (1996, p. 174). 
${ }^{8}$ Usam-se os termos com o significado da nomenclatura gramatical da época.

${ }^{9}$ Por rudimentos entenda-se a denominação dos princípios gerais da gramática: definição de gramática e de suas quatro partes, mas, essencialmente, as partes do discurso com as classes declináveis e as indeclináveis.

${ }^{10} \mathrm{Na}$ verdade, 196, porque também o fólio anterior tem como paginação 195.

${ }^{11}$ Em 1528, Erasmo publicava o diálogo De recta Latini Graecique sermonis pronuntiatione.

12 Segundo Teyssier (1980, p. 65), as realizações como uvular ou ainda como fricativa são inovações do século XIX.

${ }^{13}$ A zevra é a cedilha. Cabe notar que $\left.<\mathrm{u}\right\rangle$ e $\left.<\mathrm{v}\right\rangle$ estão em distribuição complementar nesses textos: $<\mathrm{v}>$ é empregado apenas em início de palavra.

${ }^{14}$ Vejam-se as cartilhas da época. Cabe notar, porém, que as cartilhas tinham a dupla função de introduzir o estudante na escrita não apenas do português, mas também do latim. E, no caso do latim, também essa variação era permitida: $<$ loquutus $>$ ou $<$ locutus $>$.

15 Domingos Lopes Rosa, impressor de Pacconio, não é muito conhecido. Deslandes (1888) refere a impressão de obras desse livreiro-impressor em 1639 e 1641, às quais se pode juntar o catecismo de Pacconio. Parecia não contar com $<$ ç $>$ maiúsculo, uma vez que se utilizava da maiúscula $<c>$ seguida de $<,>$ para compor AprovaçAm. O mesmo recurso para a maiúscula $<j>$. Por outro lado, a obra está cheia de diacríticos, o que parece não justificar a diferença no exemplo apontado.

${ }^{16}$ Anjiro ou, mais tarde, Paulo de Santa Fé, uma das fontes de informação de Francisco Xavier em sua viagem ao Japão.

${ }^{17}$ Fernandes (1992, p. 171): "It was .... essential to convert the Brahmins in order to baptise the rest. On the other hand, the Church in India was considered Parangi (foreign or Portuguese in a pejorative sense) and Fr. Laerzio [o Provincial Jesuíta -mcr] had written to Rome that the Brahmins were afraid that at baptism they would lose their titles, nobility and caste. De Nobili was convinced that as long as it remained a Parangi Church, Christianity would never be accepted in India”.

18 Para Roth, são 38.

${ }^{19}$ Carta aos Irmãos enfermos de Coimbra (em Anchieta, 1554 [1933], p.73-74): "Não o ponho [seu modo - mcr] em arte porque não há cá a quem aproveite, só eu me aproveito dela e aproveitar-se-ão os que de lá vierem e souberem gramática”.

20 Tradução em Freire (1671). 


\section{REFERÊNCIAS}

ALENN, W. Sidney. Vox latina. Cambridge: Cambridge University Press, 1978.

ALMEIDA, Matthew. Jesuit contribution to Indian languages. In: SOUZA, Teotônio R.; BORGES, Charles J. (Eds.). Jesuits in India: In Historical Perspective. Macau: Instituto Cultural de Macau, 1992. p. 195-208. 413 p.

ÁLVARES, Manuel. De institutione grammatica libri tres. Lisboa: João Barreiro, 1572 .

AMALADASS, Anand. Jesuits and Sanskrit studies. In: SOUZA, Teotônio R.; BORGES, Charles J. (Eds.). Jesuits in India: In Historical Perspective. Macau: Instituto Cultural de Macau, 1992. 1992. p. 209-234. 413 p.

ANCHIETA, José de. 1595. Arte de grammatica da lingua mais usada na costa do Brasil. Novamente dado à luz por Julius Platzmann. Leipzig: Teubner, 1874 .

. [1933]. Cartas: informações, fragmentos bistóricos e sermões. Belo Horizonte/São Paulo: Itatiaia/Edusp. 1988. [Reproduz Capistrano de Abreu, ed. 1933. Cartas, informações, fragmentos históricos e sermões do padre Joseph de Anchieta, S.J. (1554-1594). Rio de Janeiro: Civilização Brasileira].

ARAÚJO, Antônio de. Catecismo brasilico da doutrina christãa. Emendado pelo Padre Bartolomeu de Leão. Lisboa: Miguel Deslandes, 1686.

AZEVEDO, Gilda Maria Corrêa de. Língua kiriri: descrição do dialeto kipeá. 1965. Dissertação (Mestrado em Letras) - UnB, Brasília.

BACH, Emmon. 1965. A lingüística estrutural e a filosofia da ciência. In: COELHO, Marta et al (Orgs.). 1970. Novas perspectivas lingüisticas. Petrópolis: Vozes, 1973.

BAIÃO, Domingos Vieira. O kimbundo sem mestre. Porto: Imprensa Moderna, 1946.

BLOOMFIELD, Leonard. 1933. Language. Chicago: The University of Chicago Press, 1984. 564p.

BURKE, Peter. 1991. Heu domini, adsunt Turcae: esboço para uma história social do latim pós-medieval. In: BURKE, Peter; PORTER, Roy. 1991. Linguagem, indivíduo e sociedade: história social da linguagem. Trad. A. L. Hattnher, A. J. Gonçalves. São Paulo: UNESP, 1993. p.41-74.

CALVET, Louis-Jean. Histoire de l'écriture. Paris: Plon, 1996. 296p. 
CARDONA, George. 1990. Indian linguistics. In: LEPSCHY, Giulio (Ed.). 1990. History of linguistics: The Eastern traditions of linguistics. London: Longman, 1994. vol. 1. p.25-60.

CRYSTAL, David. An encyclopedic dictionary of language and languages. London: Penguin Books, 1992. 428 p.

CURTIUS, Ernst Robert. 1948. Literatura européia e Idade Média Latina. Trad. Paulo Rónai e Teodoro Cabral. São Paulo: Hucitec/ Edusp, 1996.

DESLANDES, Venâncio. 1888. Documentos para a bistória da tipografia portuguesa nos séculos XVI e XVII. Lisboa: Imprensa Nacional/ Casa da Moeda, 1988. Fac-símile.

DIAS, Pedro Arte de grammatica da lingua de Angola. Lisboa: Miguel Deslandes, 1697.

DIDIER, Hughes. 1996. Os portugueses no Tibete: os primeiros relatos dos Jesuítas (1624-1635). Trad. Lourdes Júdice. Coord. e fixação dos textos da edição portuguesa por Paulo Lopes Matos. Lisboa: Comissão Nacional para as Comemorações dos Descobrimentos Portugueses, 2000. 289 p.

DOKE, C.M.; COLE, D. T. Contributions to the history of Bantu linguistics. Johannesburg: Witwatersrand University Press, 1961.

ESTÊVÃO, Tomás. Arte da lingoa canarim composta pelo Padre Thomas Esteuão da Companhia de Iesus \& accrescentada pello Padre Diogo Ribeiro da mesma Companhia. E nouamente reuista. \& emendada por outros quatro Padres da mesma Companhia. Rachol: Collegio de S. Ignacio, 1640.

FERNANDES, Walter . 1992. Jesuit contribution to social change in India (16 ${ }^{\text {th }}$ to $20^{\text {th }}$ century). In: SOUZA, Teotônio R.; BORGES, Charles J. (Eds.). Jesuits in India: In Historical Perspective. Macau: Instituto Cultural de Macau, 1992. p. $157-193.413$ p.

FREIRE, João Nunes. Margens da sintaxe com a construçam portuges posta na interlinea do texto das regras della, pella Arte do Padre Manuel Alvares da Companbia de Iesu, para maior declaração aos estudantes que começam. Porto: Officina de Diogo Suares de Bulhoens, 1671.

GRIMES, Barbara F. (Ed.). Ethnologue, Languages of the world. Dallas: summer Institute of Linguistics, 1996.

HAASTRUP, Niels. Vernacular grammar as a calque of latin grammar: The case of infinitive+ skullende. In: BURSILL-HALL, G.L; EBBESEN, Sten; KOERNER, Konrad (Eds.). De ortu grammaticae: Studies in medieval grammar and linguistic theory in memory of Jan Pinborg. Amsterdam: John Benjamins, 1990. 372p. p.87-98. 
HERVÁS, Lorenzo. 1800. Catálogo de las lenguas de las naciones conocidas, y numeracion, division, y clases de estas segun la diversidad de sus idiomas y dialectos. Vol. 1: Lenguas y naciones americanas. Madrid: Imprenta de la Administracion del Real Arbitrio de Beneficencia.

JOOS, Martin (Ed.). 1957. Readings in Linguistics I: The Development of Descriptive Linguistics in America, 1925-56. Chicago: The University of Chicago Press, 1966.

LACOUTURE, Jean. 1991. Os Jesuitas: 1. Os conquistadores. Trad. de Ana Maria Capovilla. Porto Alegre: L\&PM, 1994. 531p.

LAUSBERG, Heinrich. 1956-1963. Lingüística românica. Trad. Marion Ehrhardt e M. Luísa Schemann. Lisboa: Fundação Calouste Gulbenkian, [1981]. 458p.

MALMBERG, Bertil. Histoire de la linguistique: de Sumer à Saussure. Paris: PUF, 1991.

MAMIANI, Ludovico Vincenzo. Arte de grammatica da lingua brasilica da Naçam kiriri. Lisboa: Miguel Deslandes, 1699.

Ó MATHÚNA, Seán P. 1986. William Bathe, S. J., 1564-1614: A Pioneer in Linguistics. Amsterdam: John Benjamins.

PACCONIO, Francesco. Gentio de Angola sufficientemente instruido nos mysterios de nossa sancta Fé. Obra posthuma, composta pello Padre Francisco Pacconio da Companhia de Iesu. Redusida a methodo mais breve \& accomodado á capacidade dos sogeitos, que se instruem pello Padre Antonio do Couto da mesma Companhia. Lisboa: Domingos Lopes Rosa, 1642.

PIERRARD, Pierre. 1991. História da Igreja Católica. Trad. Serafim Ferreira. Lisboa: Planeta, s.d. 375pp.

RENOU, Louis. Grammaire sanscrite. $2^{\text {ème }}$ éd. revue, corrigée et augmentée. Paris: Librairie d'Amérique et d'Orient, 1984. 568p.

RODRIGUES, Aryon. 1986. Linguas brasileiras: para o conbecimento das linguas indigenas. São Paulo: Loyola, 1994.

ROTH, Heinrich. [ca. 1660 ]. Grammatica Linguae Sanscretanae Brachmanum India Orientalis. In: The Sanskrit grammar and manuscripts of Father Heinrich Roth S.J. (1620-1668). Facsimile edition of Biblioteca Nazionale, Rome, mss. OR. 171 and 172. With an introduction by Arnulf Camps and Jean-Claude Muller, eds. Leiden: E.J. Brill, 1988. [27-122]

SOUZA, Teotônio R.; BORGES, Charles J. (Eds.). Jesuits in India: In historical perspective. [Macau]: Instituto Cultural de Macau/Xavier Center of Historical Research, 1992. 413 p. 
TEYSSIER, Paul. 1980. História da lingua portuguesa. Trad. Celso Cunha. Lisboa: Sá da Costa, 1990.

VERDELHO, Telmo. As origens da gramaticografia e da lexicografia latinoportuguesas. Aveiro: Instituto Nacional de Investigação Científica, 1995.

VINEIS, Edoardo; MAIERÙ, Alfonso. 1990. Medieval linguistics. In: LEPSCHY, Giulio (Ed.). History of Linguistics. Transl. by Emma Sansone. London: Longman, 1994. v. 2. p.134-315. 